\title{
Nerve Growth Factors (NGF, BDNF) Enhance Axonal Regeneration but Are not Required for Survival of Adult Sensory Neurons
}

\author{
Ronald M. Lindsay \\ Sandoz Institute for Medical Research, London WC1E 6BN, England
}

Largely on the basis of studies with nerve growth factor (NGF), it is now widely accepted that development of the peripheral nervous system of vertebrates is dependent in part on the interaction of Immature sensory and autonomic neurons with specific survival factors that are derived from peripheral target fields. I have found, in marked contrast to an absolute requirement for NGF during development, that adult rat dorsal root ganglion sensory neurons are not dependent on NGF or other survival factors for long-term (3-4 weeks) maintenance in vitro. When dissociated and enriched, at least $\mathbf{7 0 - 8 0 \%}$ of adult DRG neurons survived and extended long processes either in the absence of exogenously added NGF or upon the removal of any possible source of endogenous NGF or other neurotrophic activity (i.e., nonneuronal cells, in chemically defined culture medium, in the presence of an excess of anti-NGF antibodies, or when cultured as single neurons in microwells). Although not required for survival or expression of a range of complex morphologies, both NGF and brain-derived neurotrophic factor (BDNF) were found to stimulate the regeneration of axons from adult DRG neurons.

The dependence of developing neurons upon target tissue-derived neurotrophic factors (Levi-Montalcini and Angeletti, 1968; Thoenen and Barde, 1980; Barde et al., 1983; Berg, 1984) is now viewed as an epigenetic sculpting mechanism by which target tissues are able to select, from a heterogeneous pool of available neurons, only those fiber connections that will be required to carry out the specific neural functions associated with that target field at maturity. Arising from such a postulate is the question of whether such a regulatory mechanism is operative only during ontogeny or whether the survival of mature neurons is continuously dependent on target tissue-derived neurotrophic factor(s). At present, NGF still predominates as the model on which we base our understanding of the role of neurotrophic factors. Good agreement between in vivo and in vitro studies has helped to establish the view that the majority of dorsal root ganglion sensory neurons are absolutely dependent on NGF during embryogenesis and early postnatal life (see review, Lindsay, 1988). While there is some indication from in vivo studies

\footnotetext{
Received June 8, 1987; revised Oct. 26, 1987; accepted Nov. 3, 1987.

I thank Drs. Janet Winter and Tom Jessel for helpful suggestions during the course of this study, and for making improvements to early drafts of this article. I am indebted to Dr. Yves Barde for the BDNF used in this study and thank Professor Eric Shooter and colleagues for the generous gift of the 192-IgG-secreting hybridoma cell line.

Correspondence should be addressed to Dr. Lindsay, Cell Biology, Sandoz Institute for Medical Research, 5 Gower Place, London WC1E 6BN, England.

Copyright (C) 1988 Society for Neuroscience $0270-6474 / 88 / 072394-12 \$ 02.00 / 0$
}

(see review, Johnson et al., 1986) that NGF is not continuously required as a survival factor for mature sensory neurons, this issue has not previously been addressed in detail using cultures of adult sensory neurons.

Although in recent years there have been several reports of the successful culturing of adult mammalian peripheral neurons-DRG (Scott, 1977; Goldenberg and De Boni, 1983; Unsicker et al., 1985; Smith and McInnes, 1986) and of trigeminal ganglion sensory neurons (Kim et al., 1979; Fukuda and Kameyama, 1980) and superior cervical ganglion sympathetic neurons (Kim et al., 1979; Uchida and Tomonaga, 1985), it has not been possible from these studies to draw conclusions as to the neurotrophic growth factor requirements of adult neurons. In some cases, NGF was included empirically in the growth medium (Goldenberg and De Boni, 1983); in other studies, tissue extracts (e.g., chick embryo) that may contain NGF or brain-derived neurotrophic factor (BDNF)-like molecules were employed as a culture medium supplement (Fukuda and $\mathrm{Ka}$ meyama, 1980), while in most cases no attempt was made to eliminate non-neuronal cells (Scott, 1977; Kim et al., 1979; Fukuda and Kameyama, 1980; Unsicker et al., 1985), cells that had previously been shown to support the survival and/or to stimulate the outgrowth of neurites from both neonatal and adult DRG neurons (Varon et al., 1974; Wrathall, 1982; Roufa et al., 1983).

In the present study, I have compared the survival of adult rat DRG neurons cultured in the presence or absence of NGF or BDNF under conditions in which non-neuronal cells (1) were allowed to proliferate; (2) were largely eliminated at the outset by use of differential adhesion and differential sedimentation procedures, followed by treatment with antimitotic agents; (3) were suppressed with mitotic inhibitors, with cultures containing anti-NGF antibodies to block activity of any endogenous NGF; or (4) were totally absent by virtue of culturing single neurons in microwells. Under these conditions it has been possible to assess whether the survival of isolated adult sensory neurons is at all dependent on NGF or other neurotrophic factors, e.g., BDNF (Barde et al., 1982), or factors that might be derived from non-neuronal cells or the serum routinely used as culture medium supplement, and I could also assess whether NGF or BDNF influences the regeneration of the axons of adult sensory neurons. Further studies (Lindsay et al., 1987) have examined whether NGF (if not required for survival per se) may be involved in the maintenance of specific biochemical functions of mature sensory neurons, e.g., regulation of the biosynthesis of putative neuropeptide transmitters, such as substance $P$, as has been suggested from in vivo studies (Kessler and Black, 1980; Otten et al., 1980). A preliminary account of this study has appeared in abstract form (Lindsay, 1986). 


\section{Materials and Methods Cultures}

Low density. DRG (lumbar, cervical, and thoracic; 40-45;/animal) with attached roots were dissected aseptically from adult Sprague-Dawley rats (>200 gm, 3-4 months old) and collected in F-14 growth medium supplemented with $10 \%$ heat-inactivated horse serum (F14HS). Ganglia were carefully freed of roots and capsular connective tissue before being enzymatically treated $\left(37^{\circ} \mathrm{C}\right)$ and dissociated by a modification of previous procedures (Scott, 1977; Lindsay et al., 1985). Briefly, cleaned ganglia in F14HS were treated twice for $1.5 \mathrm{hr}$ with $0.125 \%$ collagenase (Boerhinger-Mannheim; clostridiopeptidase, EC. 3.4.24.3, only batches with sp act $>0.4 / \mathrm{U} \mathrm{mg}$ of lyophilisate), washed twice in $\mathrm{Ca}^{2+} / \mathrm{Mg}^{2+}$-free PBS, treated with $0.25 \%$ trypsin (Worthington; $2 \times$ crystallized) in PBS for $30 \mathrm{~min}$, washed 3 times in F14HS, and finally taken up in $2 \mathrm{ml}$ of F14HS containing DNAse (Sigma; $80 \mu \mathrm{g} / \mathrm{ml}$ ) and soybean trypsin inhibitor $(100 \mu \mathrm{g} / \mathrm{ml})$. A single-cell suspension was then readily obtained by trituration of the enzymatically softened ganglia by $6-8$ passages through the tip of a fire-polished, siliconized Pasteur pipette. The yield (conservatively estimated to be $>80 \%$ of maximum theoretical, calculated on the basis of 7000 neurons/lumbar ganglion, 6000/cervical ganglion, and $4500 /$ thoracic ganglion) of phase-bright neurons was consistently between 1.8 and $2.4 \times 10^{5}$ from $40-45$ ganglia. Cells (15005000 neurons) were either plated immediately on $35 \mathrm{~mm}$ culture dishes, previously coated with polyornithine $(500 \mu \mathrm{g} / \mathrm{ml})$ and laminin $(5 \mu \mathrm{g} /$ ml; BRL-Gibco), or plated the following day after enrichment of neurons. Neuronal enrichment was achieved by plating the dissociated ganglia from one adult in two $60 \mathrm{~mm}$ culture dishes previously coated with polyornithine. After 15-20 hr (not longer), the non-neuronal cells were firmly attached to the dish, while most of the neurons (large, phasebright cells) were only weakly adherent to the dish or to flattened nonneuronal cells. By carefully removing the culture medium, most dead cells and axonal and myelin debris were discarded prior to selectively dislodging the attached neurons with a gentle stream of culture medium delivered from a constricted Pasteur pipette. The neurons from 2 dishes were collected in a total of $12 \mathrm{ml}$ of F14HS in a conical tube. Further neuronal enrichment was achieved by centrifugation of the cell suspension at $500 \mathrm{rpm}$ for $5 \mathrm{~min}$, whereupon viable neurons were lightly pelleted, leaving myelin debris, dead cells, and small non-neuronal cells in suspension. Whether cultured immediately or after enrichment, cells were maintained at $36.5^{\circ} \mathrm{C}, 97 \%$ air: $3 \% \mathrm{CO}_{2}$, in $2 \mathrm{ml}$ of $\mathrm{F} 14 \mathrm{HS}$ supplemented with either NGF, BDNF, both or neither growth factor (control), or antiserum to mouse NGF, as before (Lindsay et al., 1985). In other experiments, serum was omitted from the growth medium and replaced by the $\mathrm{N} 1$ additives-insulin, transferrin, progesterone, putrescine, and selenium (Bottenstein, 1983). NGF was purified as previously (Lindsay et al., 1985) and BDNF, a generous gift from Dr. Y.A. Barde, was from a partially purified preparation that showed saturating activity at $500 \mathrm{ng} / \mathrm{ml}$ when tested on chick embryo DRG neurons. The number of neurons with processes longer than 4-5 cell diameters was determined under phase-contrast microscopy at $24 \mathrm{hr}, 48 \mathrm{hr}$, and other periods up to $30 \mathrm{~d}$ after plating, as before (Lindsay et al., 1985), and is expressed as a percentage of the total number of neurons originally plated in each culture dish. After $48-72 \mathrm{hr}$, the number of processbearing neurons was more or less identical to the number of surviving neurons, as few neurons without processes were apparent after this time.

Single-cell cultures. In other experiments, a suspension of cnriched adult DRG neurons was plated in polyornithine-laminin-coated Terasaki microwell plates (Nunc; 1-mm-diameter well, $10 \mu 1$ medium/well, 60 wells/plate) at a density calculated to yield 1 cell/well. To obtain adequate numbers of wells containing only a single cell, 1200-1800 wells were used in each experiment. Individual wells were scored for the presence of a single neuron (with or without processes) 4-6 hr after plating, and the same wells were then rescored for the presence of a single process-bearing neuron up to $7 \mathrm{~d}$ later. Single-cell cultures were established both in defined medium (F14 + N1 supplements) and in $10 \%$ horse serum-supplemented medium.

\section{Immunohistochemistry}

To obtain a preliminary indication that the subtypes of DRG neurons surviving in the highly enriched cultures used in this study were broadly representative of the subtypes of DRG neurons found in vivo (i.e., to ensure that those cells most likely to have any NGF responsiveness were not selectively lost at any stage during dissociation, enrichment, etc.), cultures of adult DRG neurons (enriched or nonenriched) were stained by indircct immunofluorescence with rabbit antisera to the neuropeptides substance P (a gift from Dr. A. J. Harmar, Edinburgh) and calcitonin gene-related peptide (CGRP; CRB, Camtridge, UK) and/or with antisera to the NGF receptor (Chandler et al., 1984; ascites fluid obtained from Balb/C mice inoculated with the 192-IgG-secreting hybridoma cell line, the latter kindly supplied by Prof. E. M. Shooter, Stanford University).

For labeling of the NGF receptor, living adult DRG cultures were incubated sequentially at $37^{\circ} \mathrm{C}$ for $30 \mathrm{~min}$ with $192-\mathrm{IgG}$-containing ascites fluid (1:200 dilution), biotinylated goat anti-mouse IgG (Amersham International; 1:250 dilution), and fluorescein-conjugated streptavidin (Amersham; 1:100). All reagents were diluted in F14HS and cultures were washed at least 3 times between incubations. Cultures were fixed with $4 \%$ paraformaldehyde in PBS, washed, and mounted for obscrvation under cpi-illumination in a Nikon microscope with fluorescent optics or further labeled with rabbit anti-CGRP antiserum. For substance $\mathbf{P}$ or CGRP labeling, fixed cultures were permeabilized with $0.1 \%$ Triton X-100 in PBS and then incubated overnight with antisubstance $P$ or anti-CGRP (1:1000 in PBS with $0.1 \%$ horse serum). The neuropeptide labeling was visualized with rhodamine-conjugated goat anti-rabbit IgG (1:100 dilution). Appropriate controls were carried out using nonimmune serum, direct labeling with fluorescein-coupled streptavidin, or second antibody, and blocking of the neuropeptide staining with authentic substance $P$ or rat CGRP peptide (CRB).

\section{Results}

\section{Low-density cultures}

When dissociated under optimal conditions, more than $80 \%$ of the population of adult rat DRG neurons was obtained as viable neurons (Fig. $1 A$ ). If plated without any enrichment for neurons, the resulting cultures contained predominantly non-neuronal cells even after only 1-2 d (Fig. 1B). While it is often essential in tissue culture studies to use cell type-specific markers to distinguish unambiguously between neurons and non-neuronal cells, the striking morphological differences between adult DRG neurons, Schwann cells, and fibroblasts were taken in the present study to be adequate identifying features of each cell type (Fig. $1 B)$. In the absence of mitotic inhibitors, fibroblasts and Schwann cells continued to proliferate and formed a confluent monolayer within 1 week (Fig. $1 C$ ). A high percentage ( $>60 \%$ of the viable neurons plated) of DRG neurons survived and established extensive neuritic outgrowth in such cultures in the absence of any exogenous neurotrophic factor. However, it cannot be concluded from such observaticons that adult DRG neurons do not require neurotrophic factors for survival, as factors such as NGF or BDNF may have been derived from the abundant non-neuronal cells in these cultures. To eliminate this possibility and to assess the absolute requirements and response of adult DRG neurons to NGF and BDNF, enriched cultures of neurons were obtained by separating neurons from non-neuronal cells. Freshly dissociated suspensions of adult DRG cells were left overnight on polyornithine-coated culture dishes such that highly enriched neurons were obtained 15-20 hr later (Fig. $1 D$ ) by their preferential detachment from the substrate in a gentle stream of medium that did not release the firmly adherent non-neuronal cells (Fig. $1 E$ ). By sacrificing the most adherent neurons $(<10 \%$ of the original total), by further removal of non-neuronal cells by differential sedimentation, and by including the mitotic inhibitor cytosine arabinoside $\left(10^{-5} \mathrm{M}\right)$ in the subsequent neuronal cultures, enriched cultures of DRG neurons ( $>85 \%$ neurons at the time of plating; Fig. $1 F$ ) could be maintained for several weeks.

When plated at low density (1000-3000 neurons $/ 35 \mathrm{~mm}$ dish), an extremely heterogeneous range of neuronal morphologies was observed in cultures enriched in adult DRG neurons (Fig. 2, $A-$ I). Perikaryon diameters ranged in size, as in vivo, from $<15$ 

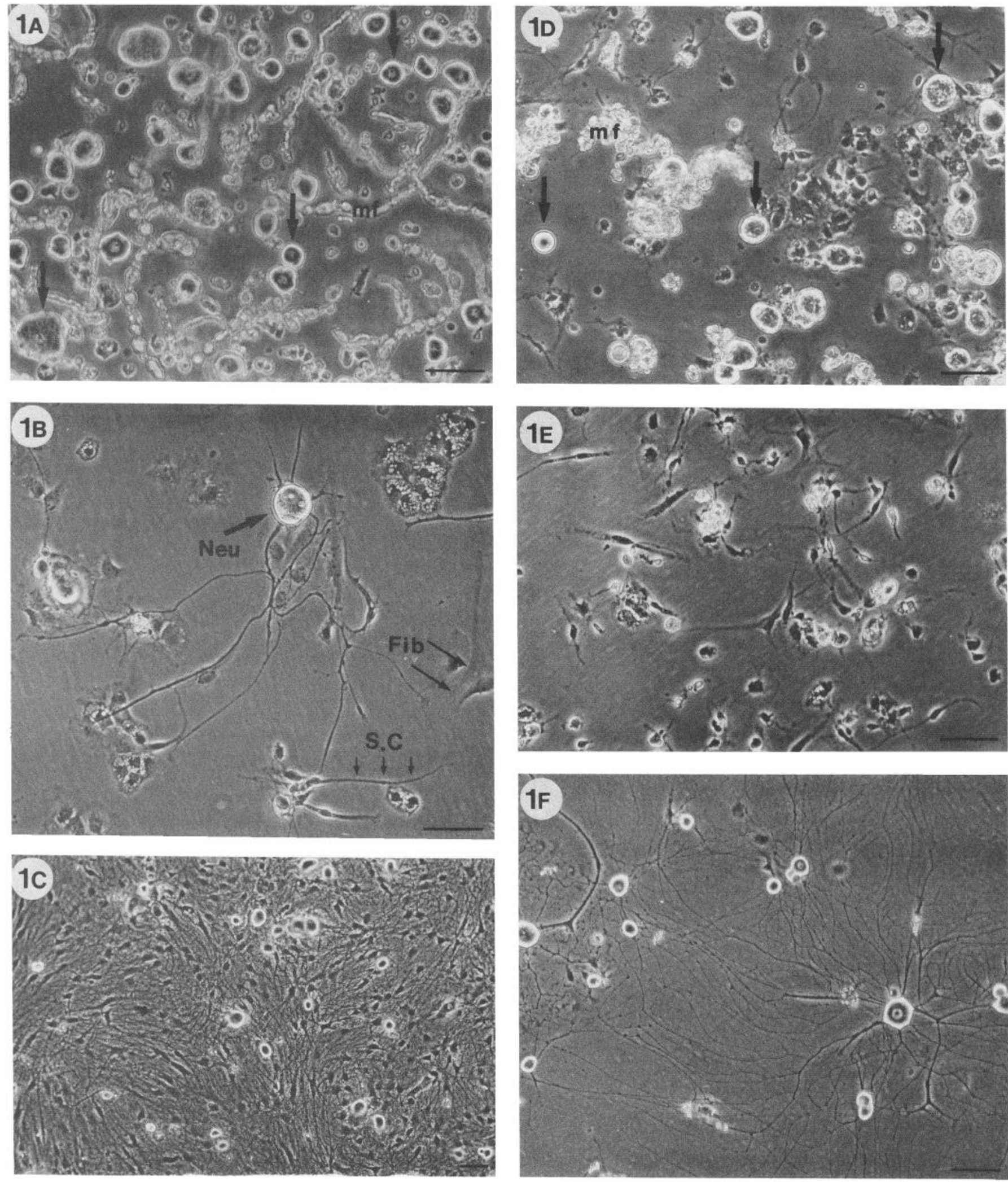

Figure 1. Phase-contrast photographs of dissociated cultures of adult rat DRG neurons plated directly after dissociation (A-C) or after neuronal enrichment $(D-F)$. A, Freshly dissociated adult DRG showing a wide range of sizes of phase-bright neuronal cell bodies (large arrows), small dark non-neuronal cells, and myelin fragments $(m f)$. B. Nonenriched culture after $48 \mathrm{hr}$ (with NGF), single phase-bright process-bearing neuron (Neu) surrounded by fibroblasts $(F i b)$ and Schwann cells (S.C.; small arrows); polyornithine-laminin substrate. $C$, Same culture as $B$ after 9 d. $D$, Dissociated adult DRG $15 \mathrm{hr}$ after plating on a polyornithine-coated dish: firmly adherent non-neuronal cells (dark cells), myelin fragments $(\mathrm{mf})$, and loosely attached neurons (large arrows) are readily visible. $E$, Same culture as $D$ after decanting the myelin debris and washing off the neurons. $F$, Highly enriched culture of adult DRG neurons ( $7 \mathrm{~d}$ in vitro, on a polyornithine-laminin-coated dish) prepared from the neurons enriched by the procedure depicted in $D$ and $E$. Scale bar, $50 \mu \mathrm{m}$. 
$\mu \mathrm{m}$ (Fig. $2 C$ ) to $>60 \mu \mathrm{m}$ (Fig. $2 H$ ), while neurite patterns ranged from pseudo-unipolar to multipolar cells, with and without extensive secondary branching and neuritic varicosities. Even in the absence of exogenous neurotrophic factors, neurons rapidly adhered to the laminin substrate, and many had short processes within $7 \mathrm{hr}$ (Fig. 2A). The presence of NGF or BDNF, however, appeared to greatly increase the initial rate of axonal regeneration from many cells (Fig. 2, $B-D$ ). While the neurite-promoting effects of NGF and BDNF were clearly visible and measurable in terms of the number of cells with and without processes in the first day or 2 in culture (Figs. 3, 4), suspected longer term neurite-promoting effects of NGF or BDNF could not be determined in this study by simple morphometric analyses, owing to great variation in the number, length, and complex branching patterns of neurites of individual cells (Fig. 2, $E-I$ ). Immunocytochemical staining of adult DRG cultures (2-10 d after plating) with antibodies to the neuropeptide substance P (12-20\% +ve) and to the calcitonon gene-related peptide CGRP (20$25 \%$ ) (RML, C. Lockett, J. Sternberger, and J. Winter, unpublished observations; and see below) has indicated that the percentage of cells containing these peptides is similar in cultures (enriched or nonenriched) to values reported in vivo (reviewed in Jessell and Dodd, 1986). This strongly suggests that the procedures used did not lead to the loss of any specific subpopulation of adult DRG neurons, especially of a small population that might be the only one with a "survival" factor requirement.

When assessed after 3 or more days in vitro, I observed within individual experiments little variation in the final number (50$80 \%$ of the neurons plated) of process-bearing neurons in cultures of adult DRG grown with or without NGF or BDNF in the presence (nonenriched) or absence (neuron-enriched) of nonneuronal cells (Fig. 3, $A$ and $B$, respectively). However, at shorter times ( 1 and $2 \mathrm{~d}$ ), and especially with cultures established immediately after dissociation (nonenriched), the percentage of process-bearing neurons in cultures supplemented with either NGF or BDNF for $1 \mathrm{~d}$ was up to 3-4-fold greater than in control cultures (Fig. $3 A$ ). In cultures that were not enriched, but in which non-neuronal proliferation was arrested with cytosine arabinoside, the number of process-bearing neurons in control cultures and cultures treated with anti-NGF antibodies (checkered bars in Fig. $3 A$ ) was essentially the same over a $17 \mathrm{~d}$ period. The latter observation largely rules out the possibility that a source of NGF endogenous to the cultures (non-neuronal or neuronal in origin) is involved in maintaining the survival of adult DRG neurons in vitro. This point was important to demonstrate, as it is clear that adult rat DRG non-neuronal cells in culture do synthesize and secrete a molecule with biological activity that can be blocked with antibodies to mouse NGF (J. Winter, unpublished observations). When dissociated neurons were enriched before plating - a procedure taking $15-20 \mathrm{hr}$-it was notable that neurite outgrowth proceeded more rapidly than was observed with neurons plated immediately after dissociation. In the experiment shown in Figure 3B, for example, 25$30 \%$ of the neurons in control cultures (cf. $10 \%$ at $1 \mathrm{~d}$ in nonenriched cultures) were already process-bearing $24 \mathrm{hr}$ after plating, a total of $44 \mathrm{hr}$ after dissociation, although the addition of NGF or BDNF to parallel cultures increased this percentage 2 -fold. By $3 \mathrm{~d}$ after plating ( $92 \mathrm{hr}$ after dissociation), the number of process-bearing neurons was more or less the same in the presence or absence of NGF or BDNF. Similar results were obtained in an experiment (Fig. 4) in which both the cells plated immediately (nonenriched) and the neurons obtained after en- richment were derived from the same initial dissociated DRG preparation. In this experiment, the neurite-promoting or axonregenerating effects of NGF were very marked in nonenriched cultures after $1 \mathrm{~d}$. Although plated $24 \mathrm{hr}$ later, the percentage of process-bearing neurons in enriched cultures was already $>45 \%$ after $1 \mathrm{~d}$ in culture ( $2 \mathrm{~d}$ after dissociation; open bar of the third group in Fig. 4). These results indicate that, after the axotomy incurred during excision and dissociation, DRG neurons require a finite period of recovery before neurite regeneration commences (Agriro and Johnson, 1982). After this period, neurite growth is rapid whether it is allowed to proceed immediately or after some delay in plating on a suitable substrate, as occurs in the course of neuron enrichment.

In most experiments, growth factors or NGF antibodies were not present during the overnight enrichment period. However, no difference in neuronal survival was observed between control cultures (no growth factor during enrichment, but subsequently growth with or without NGF, BDNF, or NGF antibodies) and cultures in which BDNF, NGF, or NGF antibodies had been present at all stages, including collection of ganglia, dissociation, and enrichment.

\section{Single-neuron cultures}

To unequivocally demonstrate that non-neuronal cells (even when present as a very minor contaminating population, i.e., $<10 \%$ ) were not supplying NGF, BDNF, or some unknown neurotrophic growth factor requirement of adult DRG neurons, enriched DRG neurons were plated at a density that yielded, on average, 1 cell/well in polyornithine-laminin-coated Terasaki (Nunc) microwell plates $(10 \mu \mathrm{l} /$ well). Four to $6 \mathrm{hr}$ after plating, wells containing only a single neuron, with no nonneuronal cells, were identified and marked. The percentage of process-bearing ncurons was detcrmincd in the marked wells at 2 and $7 \mathrm{~d}$. As shown in Table 1, up to one-quarter of the wells plated contained single neurons at 4-6 hr, and in one experiment a total of $84 \%$ of these were process-bearing at $48 \mathrm{hr}$, declining only by a net $2 \%-82 \%$ at $7 \mathrm{~d}$. The percentage of cells surviving with neurites was essentially the same in serum-supplemented or chemically defined medium, which rules out the possibility that serum contains any trophic factor for adult DRG neurons. The regeneration of neurites from an adult rat DRG neuron cultured as a single-cell culture was followed by photographic recording at $19 \mathrm{hr}$ to $7 \mathrm{~d}$ after plating (43 hr and $8 \mathrm{~d}$ after dissociation, as neuronal enrichment was carried out before plating); see Figure 5. The initial outgrowth of neurites from this cell was relatively modest at $19 \mathrm{hr}$ (Fig. 5A) compared to that from other cells observed at this time, but proceeded rapidly over the next $5 \mathrm{hr}$ (Fig. 5, B, C) with considerable branching. The single neuron continued to extend neurites over the entire period followed ( $7 \mathrm{~d}$; Fig. $5 G$ and lower-power Fig. $5 I$ ) and the cell showed no sign of deterioration after 2 weeks (not shown) in defined medium in the complete absence of any endogenous or exogenous neurotrophic factor. The lower-magnification $\mathrm{mi}$ crographs in Fig. $5 H$ ( $28 \mathrm{hr}$ after plating) and $I$ ( $7 \mathrm{~d}$ after plating), show that the microwell contained only a single cell. The small arrow in Fig. 5, $A-1$, indicates an imperfection in the plastic well that serves as a reference point. Using this point as a marker (note that Fig. 5, $D-G$, is mounted at right angles relative to the orientation of Fig. 5, $A-C$ ), it appears that the cell body of the neuron remained in a fixed location after attachment. The position and orientation of some of the neuritic network, however, did change with time, as can be seen, for example, by comparing 

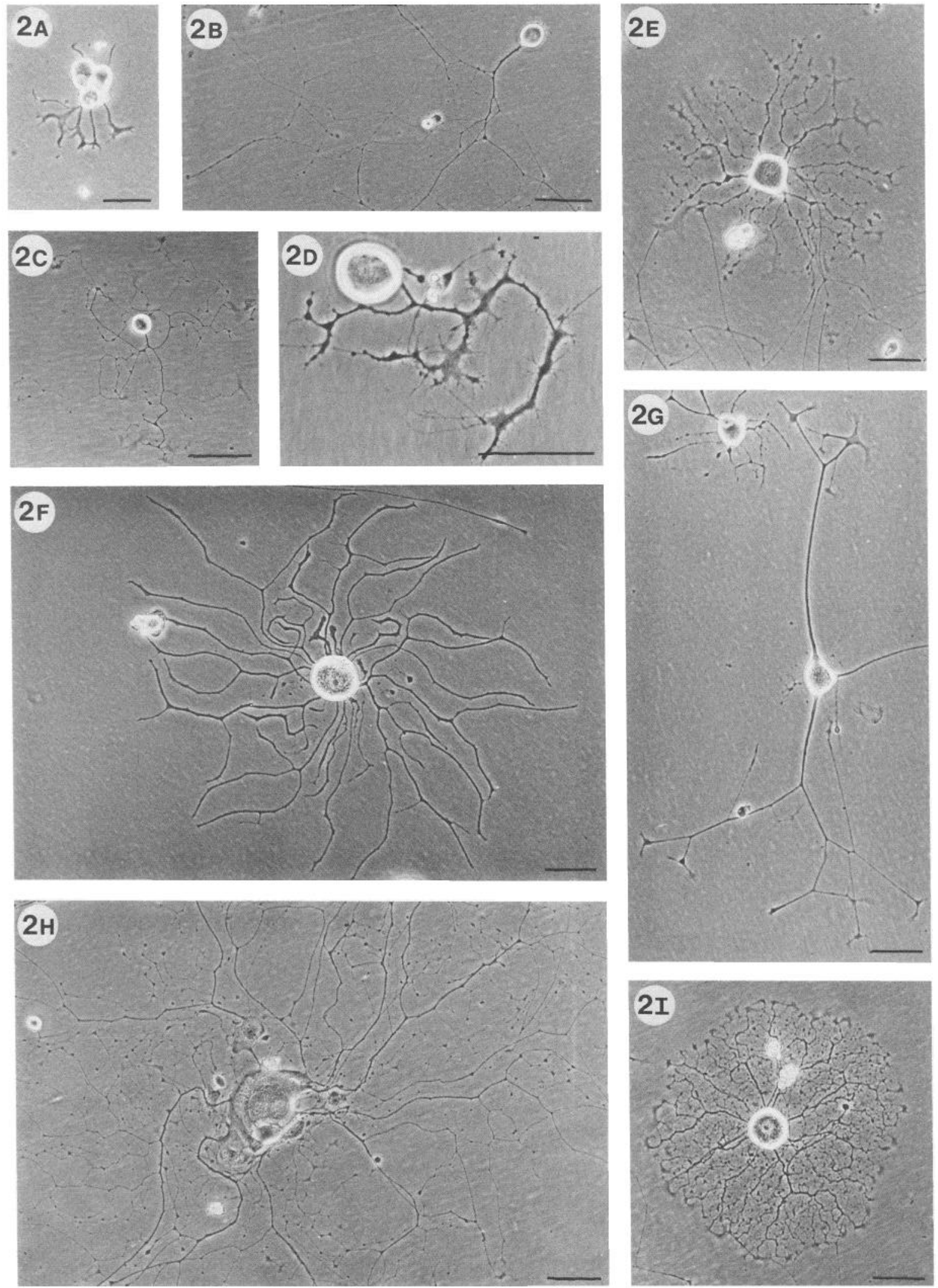

Figure 2. Phase-contrast photographs showing the heterogenous range of morphologies expressed by adult DRG neurons in neuron-enriched cultures growing on a polyornithine-laminin-coated substrate. $A-D$, All photographs taken $7 \mathrm{hr}$ after plating ( $22 \mathrm{hr}$ after dissociation). $A$, Group of neurons grown without NGF or BDNF. Note processes are too short to be scored as process-bearing neurons. $B, C$, Small-diameter, pseudounipolar neurons with extensive neurites in the presence of NGF $(50 \mathrm{ng} / \mathrm{ml}) . D$, Medium-sized neuron with very flattened growth cones; BDNF, $500 \mathrm{ng} / \mathrm{ml} . E, I$, Typical range of morphologies of adult DRG neurons in neuron-enriched cultures 24 and $48 \mathrm{hr}$ after plating (i.e., 48 and 72 after dissociation, respectively). $E$, Multipolar neuron with large neuritic varicosities; control culture, 24 hr. Note fine, straight processes of neighboring 

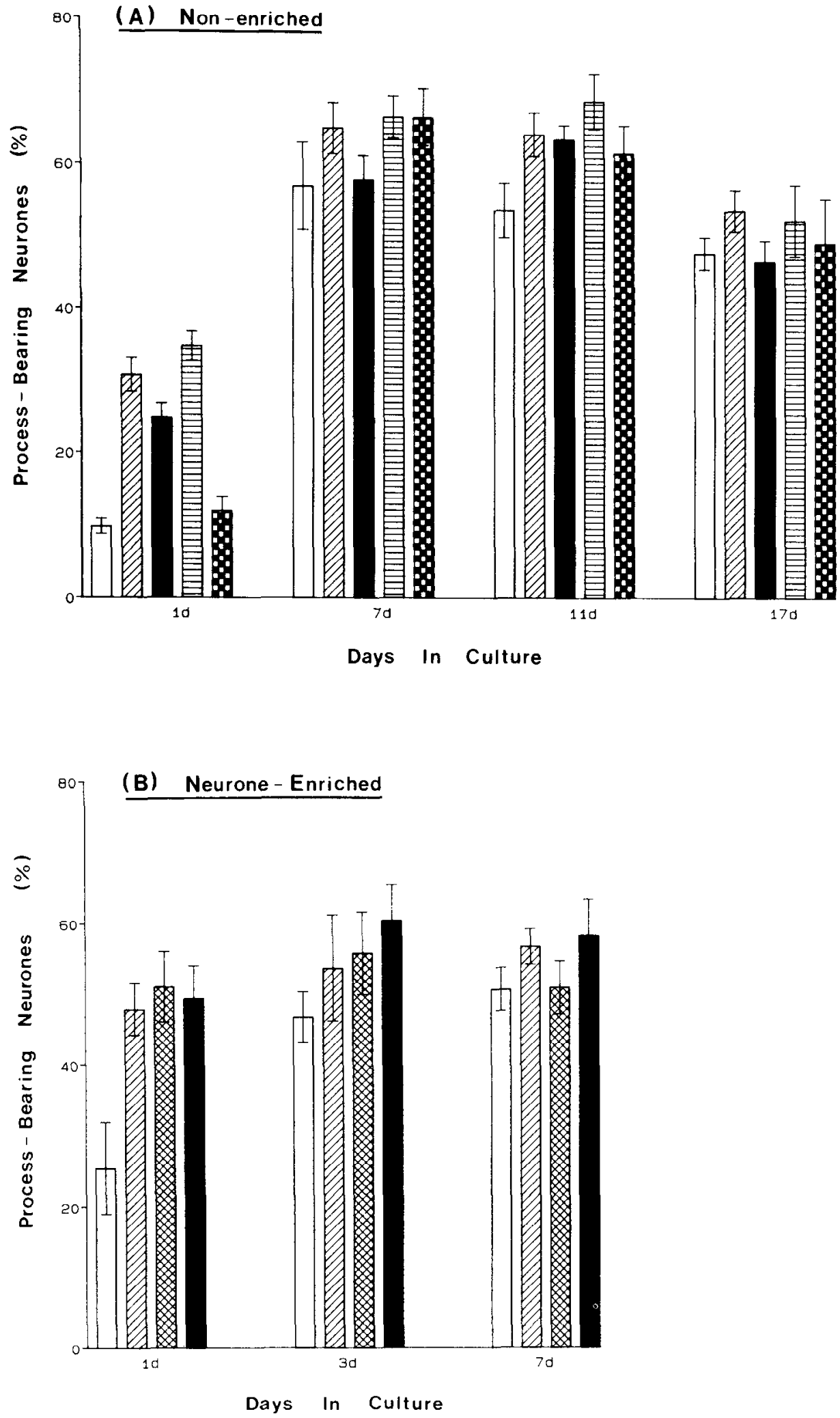

Figure 3. Bar charts comparing the percentage of process-bearing neurons in cultures of nonenriched $(A)$ and neuron-enriched $(B)$ cultures of adult rat DRG neurons. Cultures grown without (A) growth factor supplement (open bars, control cultures) or in the presence of NGF (50 ng/ml; striped bars), BDNF $(500 \mathrm{ng} / \mathrm{ml}$; solid bars $), \mathrm{NGF}+\mathrm{BDNF}$ (horizontal-striped bars), or antibodies to mouse NGF $(10 \mu \mathrm{g} / \mathrm{ml}$-sufficient to neutralize the activity of $200 \mathrm{ng}$ of mouse NGF in an E10 chick embryo DRG bioassay; checkered bars); and (B) without supplement (open bars) or with NGF $(50 \mathrm{ng} / \mathrm{ml}$, striped bars; $1 \mu \mathrm{g} / \mathrm{ml}$, cross-hatched bars) or BDNF $(500 \mathrm{ng} /$ $\mathrm{ml}$; solid bars). Triplicate cultures on polyornithine-laminin-coated dishes were established under each condition, and the number of process-bearing neurons was determined in the same dish 1-17 d after plating. Note that in neuron-enriched cultures, cells were plated $20 \mathrm{hr}$ after dissociation (i.e., $20 \mathrm{hr}$ later than similar nonenriched cultures), the time taken for the enrichment procedure. Results are expressed as the means \pm SD of triplicate cultures.

cell in the lower half of the field. $F$, Large-diameter $(40-50 \mu \mathrm{m})$, multiprocess-bearing neuron. Note thick neurites (cf. $B, C, H)$ and absence of varicosities. NGF $(50 \mathrm{ng} / \mathrm{ml}), 24 \mathrm{hr}$. $G$, Bipolar cell in control culture $24 \mathrm{hr}$ after plating (neurite at right of field is from an adjacent cell). $H$, Giantdiameter $(>70 \mu \mathrm{m})$ neuron with highly branched neurites and abundant varicosities. NGF, $48 \mathrm{hr}$. I, Medium-to-large-diameter neuron with a rosette of highly branched and varicose neurites. BDNF $(500 \mathrm{ng} / \mathrm{ml}), 48 \mathrm{hr}$. Scale bars, $50 \mu \mathrm{m}$. 


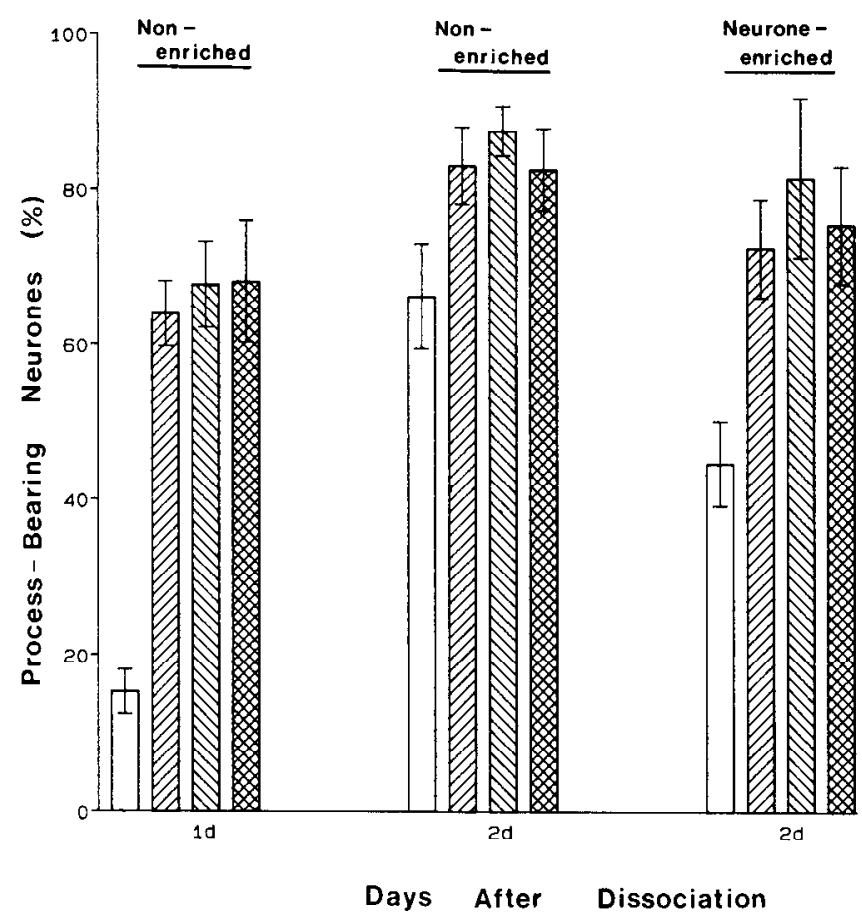

Figure 4. Bar chart comparing the percentage of process-bearing neurons in nonenriched (neurons + non-neuronal cells) and neuron-enriched cultures of adult rat DRG cells, 1 and $2 \mathrm{~d}$ after dissociation, grown with and without NGF (control cultures, open bars; NGF at 50 $\mathrm{ng} / \mathrm{ml}, 200 \mathrm{ng} / \mathrm{ml}$, and $1 \mu \mathrm{g} / \mathrm{ml}$, left-striped, right-striped, and crosshatched bars, respectively) on polyornithine-laminin-coated dishes. In this typical experiment, the yield of neurons after enrichment was $77.5 \%$ of the viable neurons obtained after dissociation, and the percentage of contaminating non-neuronal cells in the neuron-enriched cultures was $16.2 \%$ of the total cells in the culture at $2 \mathrm{~d}$. Note that, in all cases, DRG cultures were established on a substrate of laminin bound to polyornithine. Cultures grown on polyornithine alone gave similar results, but adherence and neurite outgrowth were more rapid on laminincoated dishes, resulting in a more even distribution of neurons. Results are expressed as the means \pm SD of triplicate cultures.
Figure 5, $E$ and $G$, where at $42 \mathrm{hr}(E)$ a major neuritic branch lies just under the reference arrow, while at $7 \mathrm{~d}$ the same neurite lies above the arrow. The addition of NGF to single-cell cultures was not found to increase the number of process-bearing neurons after 2 or $7 \mathrm{~d}$ in culture. Possible effects of BDNF were not lested.

Finally, to eliminate the possibility that adult DRG neurons might derive trophic support from a component of the serum routinely used as a growth medium supplement, enriched cultures (as opposed to single neurons) of adult DRG neurons were maintained in the N1 chemically defined medium, where insulin, transferrin, progesterone, putrescine, and selenium were added to the basal medium instead of serum. Up to $5 \mathrm{~d}$ in culture, the number of process-bearing neurons was almost identical ( $>65 \%$ of the cells plated) in cultures containing a scrum supplement or the N1-defined supplements. Omitting insulin from the defined medium had little effect on the number of process-bearing neurons present at $48 \mathrm{hr}$ in neuron-enriched cultures $(71.3 \pm 6.5 \%$ with insulin; $67.4 \pm 5.1 \%$ without insulin), and thus insulin does not appear to be either a survival or a neurite-promoting factor for adult DRG neurons (cf. developing sympathetic and sensory neurons; Recio-Pinto et al., 1986), although it may be required for longer-term maintenance of full metabolic function. At longer time points $(>5 \mathrm{~d})$, there was a small loss of cells in defined medium, as neurons tended to detach from the culture dish substratum in the absence of serum.

While the results of this study would indicate that the vast majority of adult rat DRG neurons do not require neurotrophic factors such as NGF for survival, I have provided preliminary evidence (Figs. 3,4 ) that NGF and BDNF may enhance the rate of neurite regeneration from adult DRG neurons and may further be involved in regulating the level of certain differentiated functions (e.g., neuropeptide levels) of mature neurons. A prerequisite for any action of NGF on adult DRG neurons would be the presence of NGF receptors on these cells. Using the antiNGF receptor monoclonal antibody 192-IgG (Chandler et al.,

\begin{tabular}{|c|c|c|c|c|}
\hline & $\begin{array}{l}\text { Wells } \\
\text { plated }\end{array}$ & $\begin{array}{l}\text { Wells with a } \\
\text { single neuron } \\
4-6 \mathrm{hr} \\
\text { after } \\
\text { plating }\end{array}$ & $\begin{array}{l}\text { Neurons (\%) } \\
\text { in col. } 2 \\
\text { surviving } \\
\text { after } 48 \mathrm{hr}\end{array}$ & $\begin{array}{l}\text { Neurons (\%) } \\
\text { in col. } 2 \\
\text { surviving } \\
\text { after } 7 \mathrm{~d}\end{array}$ \\
\hline \multicolumn{5}{|l|}{ Expt. A } \\
\hline Neurons in F14 HS(10\%) & 1200 & $284(23.7 \%)^{b}$ & $84.2(239)^{c}$ & $82.0(233)^{d}$ \\
\hline \multicolumn{5}{|l|}{ Expt. B } \\
\hline Neurons in $\mathrm{F} 14 \mathrm{HS}(10 \%)$ & 1800 & $353(19.6 \%)$ & $77.9(275)$ & $79.6(281)$ \\
\hline \multicolumn{5}{|l|}{ Expt. C } \\
\hline Neurons in F-14 $+\mathrm{N} 1$ additives $^{a}$ & 1200 & $307(25.6 \%)$ & $74.5(229)$ & $80.1(246)$ \\
\hline \multicolumn{5}{|l|}{ Expt. D } \\
\hline Neurons in F-14 + N1 additives & 1200 & $226(18.8 \%)$ & $87.1(197)$ & $75.7(171)$ \\
\hline
\end{tabular}

Note that only process-bearing neurons are scored as "surviving," and thus an increase between $48 \mathrm{hr}$ and $7 \mathrm{~d}$ indicates delayed process outgrowth by a few neurons.

a Serum-free F-14 medium + the N1 additives of Bottenstein (1983).

${ }^{b}$ Percentage of total wells plated that contained a single neuron.

- Number of single neurons counted surviving with extensive neurites at $48 \mathrm{hr}$.

${ }^{d}$ Number of single neurons counted surviving with extensive neurites at $7 \mathrm{~d}$. 

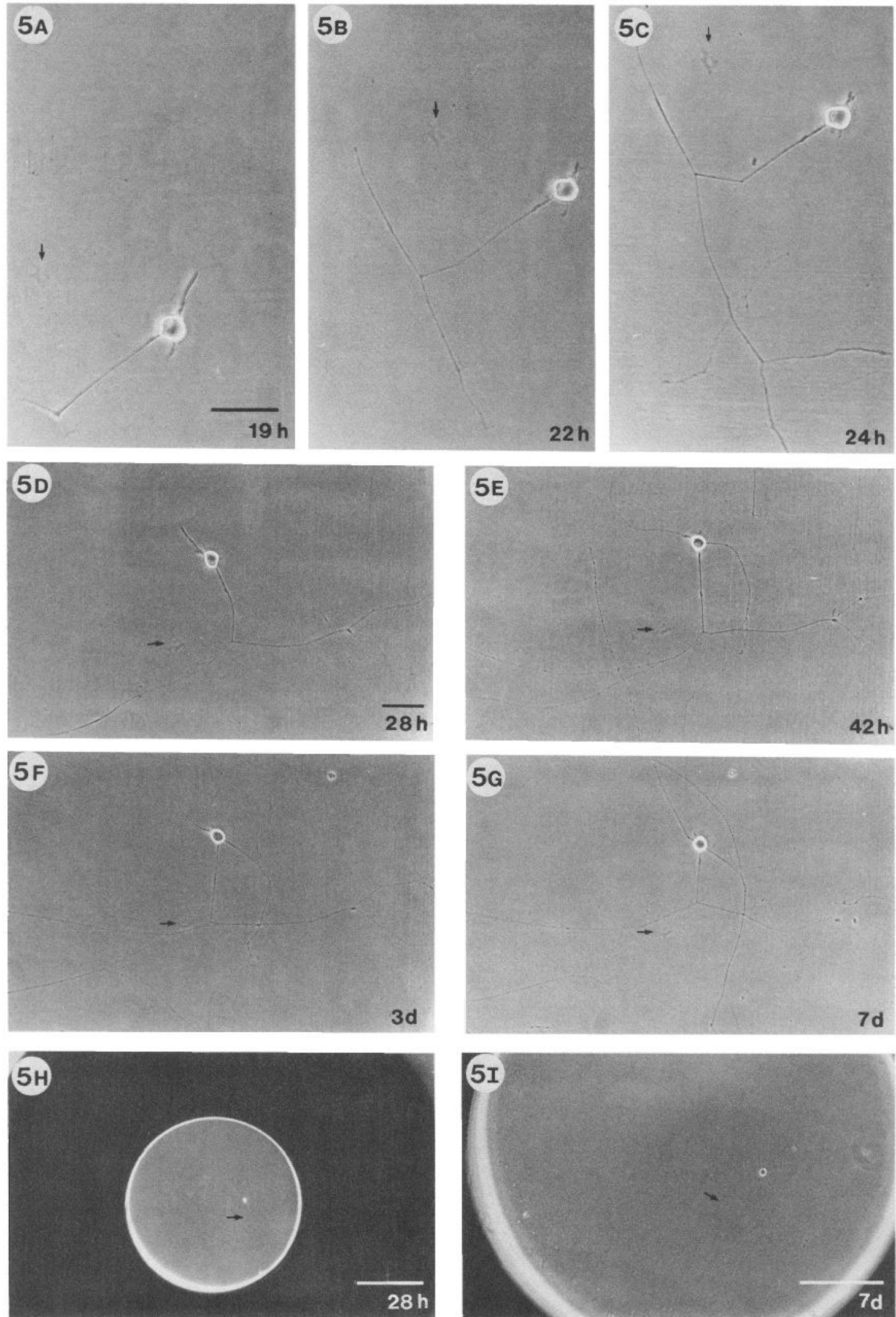

Figure 5. A series of photographs showing neurite development from a single adult rat DRG neuron, cultured as an isolated cell in a microwell (coated with polyornithine-laminin) in defined cultured medium (serum-free) in the absence of any exogenous neurotrophic factor. Photographs were taken at $19 \mathrm{hr}(A), 22 \mathrm{hr}(B), 24 \mathrm{hr}(C), 28 \mathrm{hr}(D, H), 42 \mathrm{hr}(E), 3 \mathrm{~d}(F)$, and $7 \mathrm{~d}(G, I)$. The small arrow in each photograph marks an imperfection in the culture dish, which serves as a fixed reference point. Note that $D-I$ are mounted at right angles to $A-C$. $A-C$ are at the same magnification, as are $D-G$. Verification that this cell was cultured in isolation can be seen in $H$. Scale bar: $50 \mu \mathrm{m}(A-G) ; 400 \mu \mathrm{m}(H) ; 200 \mu \mathrm{M}(I)$. 


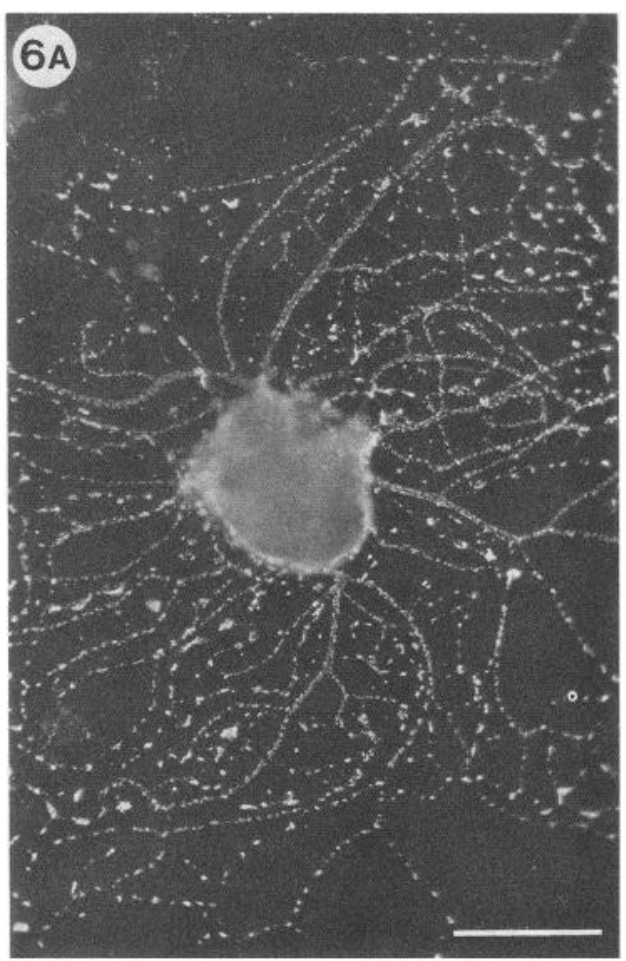

Figure 6. Immunofluorescence photographs of adult DRG neurons stained with antibodies to either the NGF receptor $(A, C)$ or to the calcitonin generelated peptide (CGRP) $(B, D)$. $A$, Large adult DRG neuron, $2 \mathrm{~d}$ in culture, showing intense patchy staining after labeling with antibodies to the NGF receptor, visualized with a biotinylated second antibody and fluorescein-conjugated streptavidin. Staining was carried out on the living cell at $37^{\circ} \mathrm{C}$, which probably results in receptor clustering and the patchy appearance of fluorescence on the large, multiple neurites. $B$, Neurite and growth cone of an adult DRG neuron brightly stained with antiCGRP antibodies (visualized with a rhodamine-conjugated second antibody) after only $2 \mathrm{~d}$ in culture. The cell body and processes of an unlabeled neuron can be seen in the lower left portion of the photograph. $C, D$, The same neuron ( $2 \mathrm{~d}$ in culture) doublelabeled with anti-NGF receptor antibodies $(C$, photographed with fluorescein filter) and CGRP antibodies $(D$, photographed with rhodamine filter). About $35 \%$ of NGF receptor-positive neurons were also CGRP-positive, but $5 \%$ of CGRP-positive neurons lacked NGF receptors. Scale bar, $50 \mu \mathrm{m}$.

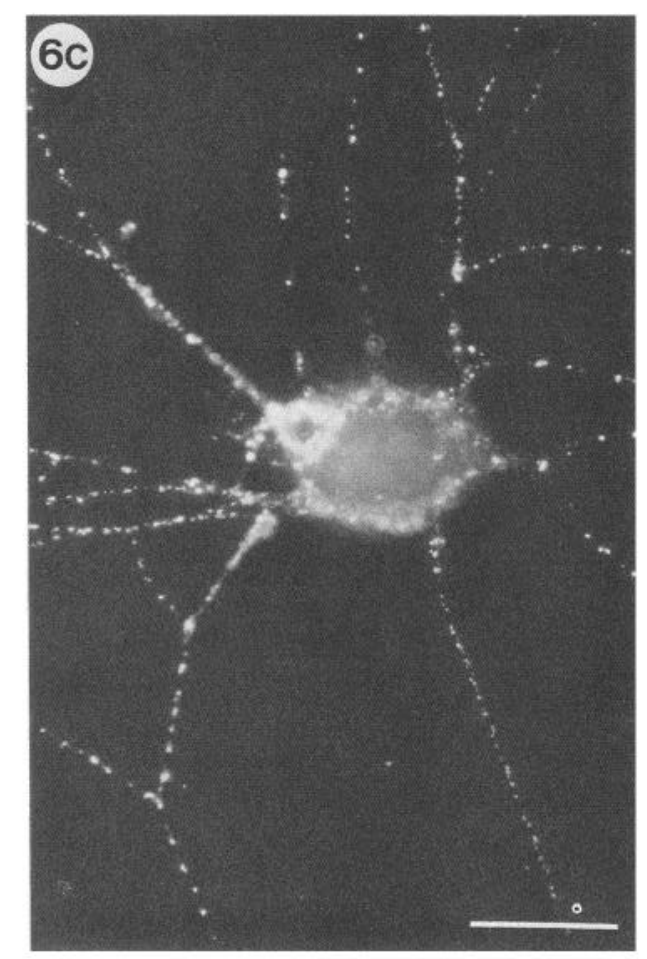

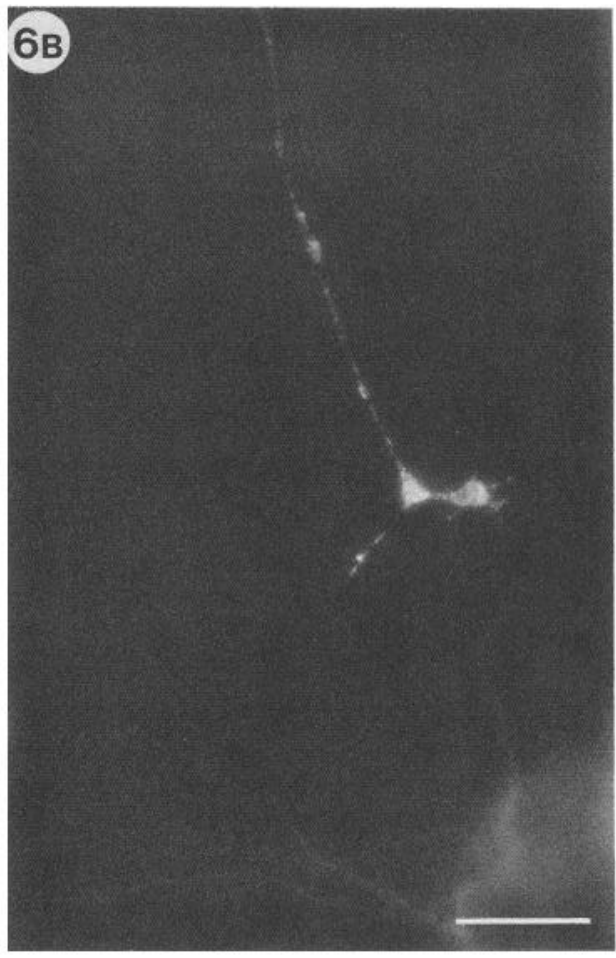

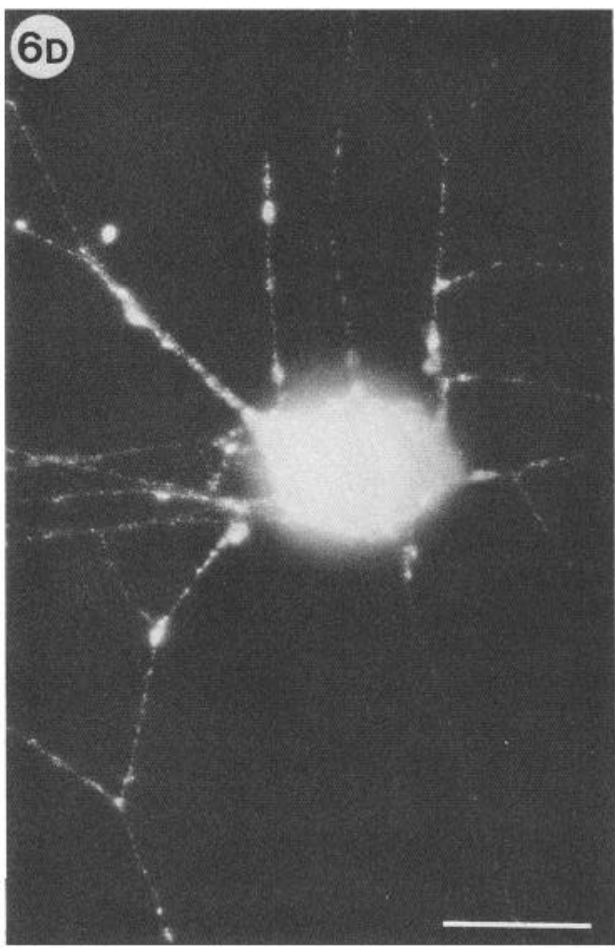

1984), abundant NGF receptors were detected on the majority $(>60 \%)$ of adult DRG neurons after $1-7 \mathrm{~d}$ in vitro. When living cells were incubated with the anti-NGF receptor, monoclonal patchy staining was observed over all the neurites (Fig. $6 A$ ) of labeled cells. The patchy appearance of the fluorescence suggests that binding of the antibody induces clustering of receptors over the $1.5 \mathrm{hr}$ incubation period at $37^{\circ} \mathrm{C}: 30 \mathrm{~min} 192-$
IgG ascites; 30 min biotinylated 2 nd antibody; 30 min fluorescein isothiocyanate-(FITC)-streptavidin. When cells were fixed with $4 \%$ paraformaldehyde before labeling, the staining pattern was more uniform, but less intense (not shown). Preliminary studies with antibodies to the neuropeptides substance $\mathrm{P}$ and CGRP indicated that the percentage of adult DRG neurons containing these peptides in vitro was similar to that found in 

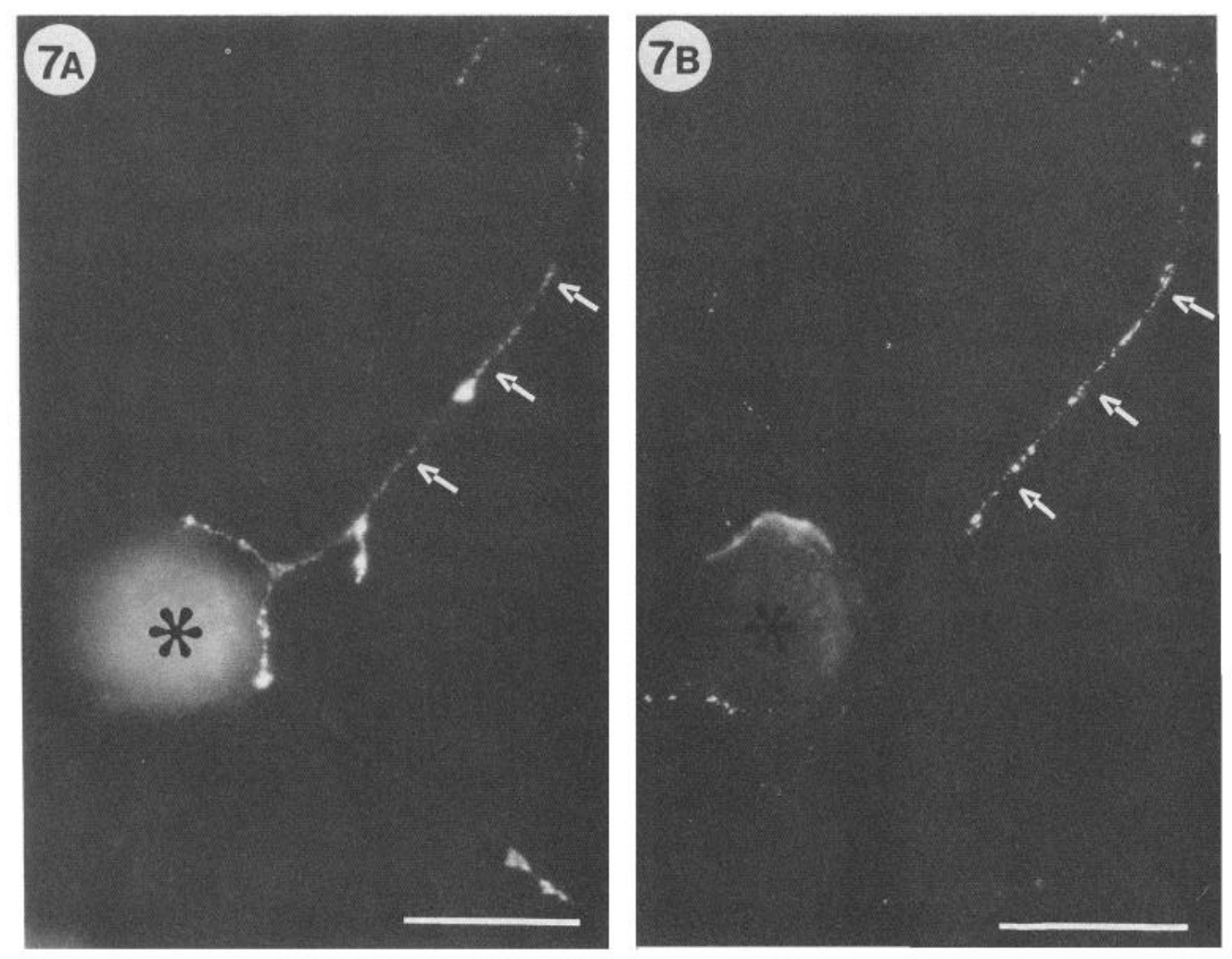

Figure 7. Immunofluorescence photographs of the same field of a culture of adult DRG neurons double-labeled with antibodies to substance $\mathrm{P}(A)$ and antibodies to the NGF receptor $(B)$. Note coincidence (arrows in $A$ and $B$ ) of substance $P$ and NGF receptor labeling in a neurite that has terminal branches around the cell body of an adjacent, unlabeled cell. The latter can be seen (asterisk, $A$ ) owing to relatively high background fluorescence with the rhodamine filter. Double-labeling was carried out as in Materials and Methods; see also legend to Figure 6. Neurons were in culture $2 \mathrm{~d}$ with NGF before staining. At this stage, substance $P$ staining was weak in cell bodies (not shown), but abundant in neurites and their terminals. Scale bar, $50 \mu \mathrm{m}$.

vivo. Qualitatively, at least, CGRP appeared to be very abundant in positive cells and was readily detected in cell bodies and neurites after only $2 \mathrm{~d}$ in culture (Fig. $6 \mathrm{~B}$ ). By visualization of NGF receptor immunoreactivity with fluorescein-coupled streptavidin, and visualization of CGRP immunoreactivity with a rhodamine-coupled second antibody, it was found that the majority ( $>90 \%$ ) of CGRP-immunoreactive neurons possessed NGF receptors (Fig. 6, C, D). A similar colocalization of NGF receptors and substance $P$ immunoreactivity was found (Fig. 7, $A, B)$, although qualitatively substance $\mathrm{P}$ staining was less intense in cell bodies, especially after only a short period in vitro.

Taken together, the above results indicate that adult DRG neurons have the potential to be responsive to NGF, even though NGF is not required as a survival factor.

\section{Discussion}

As a consequence of its fortuitous abundance in the adult male mouse salivary gland and of its spectacular effects on promoting neurite outgrowth from explanted sympathetic and dorsal root ganglia, NGF has served well as an archetypal neurotrophic molecule with which to test concepts of neurotrophism in the peripheral nervous system. While the role of NGF as a survival factor for developing postmitotic sympathetic neurons and DRG sensory neurons has been clearly and repeatedly demonstrated, some of the roles or functions that have been ascribed to NGF remain far from proven. With regard to the full developmental sequence of sensory neurons, for example, some of the outstanding questions have concerned the role (if any) of NGF in (1) the guidance or attraction, at very early developmental stages, of growing fibers to their peripheral target field; (2) development of sensory neurons other than those of DRG, i.e., cranial sensory ganglia; (3) sustaining the survival or maintaining the fully differentiated status of mature adult sensory neurons. Although a possible tropic role for NGF in guiding or attracting developing sensory fibers to their targets was suggested from the results of in vitro studies by Gundersen and Barrett (1979) a few years ago, recent studies that have focused carefully on temporal aspects of the development of the trigeminal ganglion and its peripheral target field tend to rule out any tropic role for NGF in development (Lumsden and Davies, 1983, 1986; Davies et al., 1987). This conclusion is drawn from experiments that have shown that NGF does not promote neurite outgrowth ab initio from cultured explants, that factors other than NGF guide developing fibers to their peripheral target, that sensory nerve fibers do not possess NGF receptors in vivo until shortly before or after they reach their peripheral target tissue, and that there is no synthesis of NGF in peripheral structures until about the time they become innervated. With regard to sensory neurons other than those of DRG, recent studies have indicated that a survival role of NGF may be confined to neural crest-derived sensory neurons, while sensory neurons of placodal origin are insensitive to NGF but dependent on other neurotrophic factors (Davies and Lindsay, 1985; Lindsay and Rohrer, 1985; Lindsay et al., 1985).

The present study was initiated with a view to providing a possible answer to the third question above, i.e., are fully mature sensory neurons at all dependent on NGF or other neurotrophic factors for survival? While this question has been addressed experimentally in vivo (see Johnson et al., 1986, for a review), with somewhat ambiguous results, there has been surprisingly little use of dissociated cell culture methods to help to define 
the growth factor requirements or responses of adult sensory neurons. The feasibility of maintaining adult peripheral neurons in vitro has been established for more than a decade (Scott, 1977), and isolated adult rat DRG neurons have found increasing favor as an electrophysiological preparation. However, to obtain any meaningful information on the growth factor requirements of adult DRG neurons in vitro, it has been necessary to isolate the neurons from any possible source of endogenous neurotrophic activity, such as non-neuronal cells, other neurons, scrum supplement, ctc. I have thus shown that the vast majority of adult sensory neurons survive in culture equally well in the presence or absence of non-neuronal cells (cf. in enriched and nonenriched cultures; Figs. 3, 4).

For several reasons, it is difficult to arrive at a very accurate estimate of the upper limit for the percentage of adult DRG neurons that can survive in the absence of neurotrophic factors. Most important, there are no absolute values that can be used with confidence to calculate the expected yield of neurons from any defincd pool of rat lumbar, thoracic, and ccrvical ganglia. This limitation is imposed not only because there is wide variation in published values (determined by histological means) of neuronal number in rat DRG at specific segmental levels, but because detailed studies have shown that there are very substantial interanimal differences in the total number of DRG neurons in pools of lumbar or thoracic ganglia. For example, Ygge et al. (1981) have shown an interanimal range of 55,00075,000 neurons for the total number of neurons in thoracic ganglia $1-13$ of adult rats. Arvidsson et al. (1986) have similarly shown an interanimal range of 26,400-47,900 neurons for all neurons within a pool comprising the right and left lumbar ganglia L4, L5, and L6 of adult Sprague-Dawley rats. In view of these limitations, and also allowing for the inevitable and somewhat variable loss of cells during experimental procedures, the conclusions I have drawn are conservative and most likely underestimate the percentage of adult DRG neurons whose survival is independent of NGF or BDNF.

To be absolutely certain that non-neuronal cells were completely absent from the cultures, single neurons were grown in microwells, where a high survival $(>80 \%)$ was observed for at least 1 week (Table 1) in the absence of any neurotrophic factor, such as NGF or BDNF, and in the absence of any serum (i.e., in N1-defined medium).

By the very nature of the procedures employed, a certain percentage of neurons are lost during preparation of the cultures (mechanical damage, loss during enrichment, etc.). It is, however, highly unlikely that there was preferential loss of any particular subpopulation of neurons, as the percentage of cells in culture showing immunoreactivity for the neuropeptides CGRP and substance $\mathrm{P}$ was found to be very similar to that reported in vivo (see above and RML, C. Lockett, J. Sternberger, and J. Winter, unpublished observations). No difference was observed between the percentages of neuropeptide-containing cells in enriched and nonenriched cultures.

While most of the results in this study were derived from cultures established on polyornithine-laminin-coated tissue culture dishes, similar results were found when polyornithine alone served as the substrate. The benefit of laminin, however, was that adult neurons attached to it much more rapidly than to polyornithine. Rapid adhesion was desirable to achieve a uniform distribution of adult DRG neurons over the culture dish, as well-dispersed cells (as opposed to clumps) greatly facilitated the quantitation of process-bearing neurons. Laminin alone did not appcar to influcnce the survival of adult DRG neurons, nor did laminin potentiate any effects of NGF or BDNF. This is in contrast to findings with embryonic chick sensory neurons, in which laminin was found to potentiate the survival-promoting effects of BDNF in cultures of E6 DRG neurons (Lindsay et al., 1985).

I conclude from the present experiments that neurotrophic factors such as NGF and BDNF are not required as survival factors by the vast majority of adult DRG sensory neurons. This finding is in broad agrecment with several studies that have shown that antibodies to NGF have little or no effect on the survival of adult DRG neurons in vivo (Gorin and Johnson, 1980; Schwartz et al., 1982; Rich et al., 1984). It has recently been reported, however, that the survival of at least a subpopulation of adult DRG neurons after axotomy is dependent on some form of trophic support derived from either their peripheral or central target (Johnson and Yip, 1985). While many investigators have shown that there is some loss of neurons in adult DRG cells following axotomy of their peripheral processes, it cannot be assumed, as has been suggested (see review by Johnson et al., 1986), that this cell death is entirely due to loss of supply of a peripheral target-derived growth factor, such as NGF. The growth factor-independent survival of cultured adult DRG neurons is in marked contrast to the absolute NGF requirement of at least $50 \%$ of developing DRG neurons, as determined from both in vivo and in vitro studies (Levi-Montalcini and Angeletti, 1968; Johnson et al., 1980; Lindsay, 1988). NGF and BDNF, however, do appear to markedly enhance the initial onset of axonal regeneration from cultured adult DRG sensory neurons, and NGF also produces a very marked elevation of substance $\mathrm{P}$ levels (as determined by radioimmunoassay; Lindsay et al., 1987, and RML, C. Lockett and J. Winter, unpublished observations), as has been reported in vivo (Kessler and Black, 1980; Otten et al., 1980). Experiments are in progress to determine the longer-term neurite-promoting effects of NGF and BDNF on axotomized adult DRG neurons, information that may have a direct bearing on the possible clinical use of NGFs.

\section{References}

Argiro, V., and M. I. Johnson (1982) Patterns and kinetics of neurite extension from sympathetic neurons in culture are age dependent. J. Neurosci. 2: 503-512.

Arvidsson, J., J. Ygge, and G. Grant (1986) Cell loss in lumbar dorsal root ganglia and transganglionic degeneration after sciatic nerve resection in the rat. Brain Res. 373: 15-21.

Barde, Y.-A., D. Edgar, and H. Thoenen (1982) Purification of a new neurotrophic factor from mammalian brain. EMBO J. 1: 549-553.

Barde, Y.-A., D. Edgar, and H. Thoenen (1983) New neurotrophic factors. Annu. Rev. Physiol. 45: 601-612.

Berg, D. K. (1984) New neuronal growth factors. Annu. Rev. Neurosci. 7: $140-170$.

Bottenstein, J. E. (1983) Growth requirement of neural cells in vitro. Adv. Cell. Neurobiol. 4: 333-379.

Chandler, C. E., L. M. Parsons, M. Hosang, and E. M. Shooter (1984) A monoclonal antibody modulates the interaction of nerve growth factor with PCl 2 cells. J. Biol. Chem. 259: 6882-6889.

Davies, A. M., and R. M. Lindsay (1985) The cranial sensory ganglia in culture: Differences in the response of placode-derived and neural crest-derived neurons to nerve growth factor. Dev. Biol. 111:62-72.

Davies, A. M., C. Bandtlow, R. Heumann, S. Korsching, H. Rohrer, and $H$. Thoenen (1987) Timing and site of nerve growth factor synthesis in developing skin in relation to innervation and expression of the receptor. Nature 326: 353-358.

Fukuda, J., and M. Kameyama (1980) A tissue culture of nerve cells from adult mammalian ganglia and some electrophysiological properties of nerve cells in vitro. Brain Res. 202: 249-255. 
Goldenberg, S. S. S., and U. De Boni (1983) Pure population of viable neurons from rabbit dorsal root ganglia, using gradients of Percoll. J. Neurobiol. 14: 195-206.

Gorin, P. D., and E. M. Johnson (1980) Effects of long-term nerve growth factor deprivation on the nervous system of the adult rat: An experimental autoimmune approach. Brain Res. 198: 27-42.

Gundersen, R. W., and J. N. Barrett (1979) Neuronal chemotaxis: Dorsal root axons turn towards high concentrations of nerve growth factor. Science 206: 1079-1080.

Jessell, T. M., and J. Dodd (1986) Neurotransmitters and differentiation antigens in subsets of sensory neurons projecting to the spinal dorsal horn. In Neuropeptides in Neurologic and Psychiatric Disease J. B. Martin and J. D. Barchas, eds., pp. 111-133, Raven, New York.

Johnson, E. M., Jr., and H. K. Yip (1985) Central nervous system and peripheral nerve growth factor provide trophic support critical to mature sensory neuronal survival. Nature 314: 751-752.

Johnson, E. M., P. D. Gorin, L. D. Brandeis, and J. Pearson (1980) Dorsal root ganglion neurons are destroyed by exposure in utero to maternal antibody to nerve growth factor. Science 210:916-918.

Johnson, E. M., M. Rich, and H. K. Yip (1986) The role of NGF in sensory neurons in vivo. Trends Neurosci. 9: 33-37.

Kessler, J. A., and I. B. Black (1980) Nerve growth factor stimulates development of substance $\mathbf{P}$ in sensory ganglia. Proc. Natl. Acad. Sci. USA 77: 649-652.

Kim, S. U., K. G. Warren, and M. Kalia (1979) Tissue culture of adult human neurons. Neurosci. Lett. 11: 137-141.

Levi-Montalcini, R., and P. U. Angeletti (1968) Nerve growth factor. Physiol. Rev. 48: 534-569.

Lindsay, R. M. (1986) Nerve growth factors enhance neurite regeneration but are not required as survival factors for adult sensory neurons in culture. Soc. Neurosci. Abstr. 12: 1098.

Lindsay, R. M. (1988) The role of neurotrophic growth factors in development, maintenance and regeneration of sensory neurons. In The Making of the Nervous System, J. Parnavelas, C. D. Stern, and R. V. Stirling, eds., pp. 148-165, Oxford U. P.

Lindsay, R. M., and H. Rohrer (1985) Placodal sensory neurons in culture: Nodose ganglion neurons are unresponsive to NGF, lack NGF receptors but are supported by a liver-derived neurotrophic factor. Dev. Biol. 112: 30-48.

Lindsay, R. M., H. Thoenen, and Y.-A. Barde (1985) Placode and neural crest-derived sensory neurons are responsive at early developmental stages to brain-derived neurotrophic factor. Dev. Biol. 112. 319-328.

Lindsay, R. M., C. Lockett, and J. Winter (1987) Nerve growth factor modulation of neuropeptide levels in adult sensory neurons in culture Soc. Neurosci. Abstr. 13: 518.
Lumsden, A. G. S., and A. M. Davies (1983) Earliest sensory nerve fibres are guided to peripheral targets by attractants other than nerve growth factor. Nature 306: 786-788.

Lumsden, A. G. S., and A. M. Davies (1986) Chemotrophic effect of specific target epithelium in the developing mammalian nervous system. Nature 323: 538-539.

Otten, U., M. Goedert, N. Mayer, and F. Lembeck (1980) Requirement of nerve growth factor for development of substance P-containing sensory neurones. Nature 287: 158-159.

Recio-Pinto, E., M. M. Rechler, and D. N. Ishii (1986) Effects of insulin-like growth factor-II, and nerve growth factor on neurite formation and survival in cultured sympathetic and sensory neurons. $J$. Neurosci. 6: 1211-1219.

Rich, K. M., H. K. Yip, P. A. Osborne, R. E. Schmidt, and E. M Johnson, Jr. (1984) Role of nerve growth factor in the adult dorsal root ganglia and its response to injury. J. Comp. Neurol. 230: 110118.

Roufa, D. G., M. I. Johnson, and M. B. Bunge (1983) Influence of ganglion age, nonneuronal cells and substratum on neurite outgrowth in culture. Dev. Biol. 99: 225-239.

Schwartz, J. P., J. Pearson, and E. M. Johnson, Jr. (1982) Effect of exposure to anti-NGF on sensory neurons of adult rats and guinea pigs. Brain Res. 244: 378-381.

Scott, B. S. (1977) Adult mouse dorsal root ganglia neurons in cell culture. J. Neurobiol. 8: 417-427.

Smith, R. A., and I. B. McInnes (1986) Phase contrast and electron microscopical observations of adult mouse dorsal root ganglion cells maintained in primary culture. J. Anat. 145:1-12.

Thoenen, H., and Y.-A. Barde (1980) Physiology of nerve growth factor. Physiol. Rev. 60: 1284-1335.

Uchida, Y., and M. Tomonaga (1985) Nerve growth factor accelerates regeneration of cultured adult sympathetic ganglion cells. Age 8: 1920.

Unsicker, K., S. D. Skaper, G. E. Davis, M. Manthorpe, and S. Varon (1985) Comparison of the effects of laminin and the polyornithinebinding neurite promoting factor from RN22 schwannoma cells on neurite regeneration from cultured newborn and adult rat dorsal root ganglion neurons. Dev. Brain Res. 17: 304-308.

Varon, S., C. Raiborn, and P. A. Burnham (1974) Selective potency of homologous ganglionic non-neuronal cells for the support of dissociated ganglionic neurons in culture. Neurobiology 4: 231-252.

Wrathall, J. R. (1982) Effect of nonneuronal cells on the regeneration of adult sensory neurons in culture. J. Cell Biol. 95: 9A.

Ygge, J., H. Aldskogius, and G. Grant (1981) Asymmetries and symmetries in the number of thoracic dorsal root ganglion cells. J. Comp. Neurol. 202: 365-372. 